\title{
Mammalian achaete-scute homolog 1 is transiently expressed by spatially restricted subsets of early neuroepithelial and neural crest cells
}

\author{
Li-Ching Lo, Jane E. Johnson, Carol W. Wuenschell, ${ }^{1}$ Tetsuichiro Saito, and David J. Anderson ${ }^{2}$ \\ Division of Biology 216-76, Howard Hughes Medical Institute, California Institute of Technology, Pasadena, California \\ 91125 USA
}

\begin{abstract}
Using monoclonal antibodies, we have examined the expression pattern of MASH1, a basic helix-loop-helix protein that is a mammalian homolog of the Drosophila achaete-scute proteins. In Drosophila, achaete-scute genes are required for the determination of a subset of neurons. In the rat embryo, MASH1 expression is confined to subpopulations of neural precursor cells. The induction of MASH1 precedes, but is extinguished upon, overt neuronal differentiation. MASH1 is expressed in the forebrain by spatially restricted domains of neuroepithelium and in the peripheral nervous system exclusively by precursors of sympathetic and enteric neurons. The features of early and transient expression, in spatially restricted subpopulations of neural precursors, are similar to those observed for achaete-scute. Thus, the amino acid sequence conservation between MASH1 and achaete-scute is reflected in a parallel conservation of cell type specificity of expression, similar to the case of mammalian MyoD and Drosophila nautilus. These data support the idea that helix-loop-helix proteins may represent an evolutionarily conserved family of cell-type determination genes, of which MASH1 is the first neural-specific member identified in vertebrates.
\end{abstract}

[Key Words: Helix-loop-helix proteins; neuronal determination; forebrain; achaete-scute genes; nuclear regulatory factor; neural crest development]

Received June 21, 1991; accepted July 10, 1991.

The achaete-scute complex (AS-C) of Drosophila melanogaster contains a family of related genes whose function is required for the determination of certain neurons (García-Bellido and Santamaria 1978; García-Bellido 1979; Ghysen and Dambly-Chaudiere 1988). Mutations in different genes of the complex prevent the appearance of positionally restricted subsets of sensory mother cells within the peripheral nervous system (PNS) (DamblyChaudiere and Ghysen 1987). The AS-C is also required for neuronal determination within the central nervous system (CNS) (Cabrera et al. 1987). Genes of the AS-C are known to interact genetically with a number of other loci, including daughterless $(d a)$, hairy $(h)$, extramachrochaete (emc), and several neurogenic genes such as Notch and Delta (Moscoso del Prado and García-Bellido 1984; Dambly-Chaudiere et al. 1988; Cabrera 1990). These genetic interactions have led to the idea that the achaete-scute genes participate in a regulatory network that defines territories within the epithelium where sen-

\footnotetext{
${ }^{1}$ Present address: Norris Cancer Center, University of Southern California, Los Angeles, California 90033-0800 USA.

${ }^{2}$ Corresponding author.
}

sory organs will develop (Ghysen and Dambly-Chaudiere 1989|. However, the precise role of these genes in the process of neuroblast determination is still not clear.

New insights into the function and regulation of AS-C genes have emerged from the determination of their nucleotide sequences (Campuzano et al. 1985; Villares and Cabrera 1987; Gonzalez et al. 1989) and from biochemical studies of structurally related genes in mammalian systems (Murre et al. 1989b; Davis et al. 1990). The achaete-scute proteins are members of a family of transcription factors with common dimerization and DNA-binding motifs, called the basic helix-loop-helix (bHLH) family (Murre et al. 1989a,b). Another bHLH protein, called $\mathrm{MyoD}$, is involved in myogenic determination in vertebrates (Davis et al. 1987), suggesting that the bHLH motif may define a family of cell-type determination genes (Weintraub et al. 1991). In vitro studies of MyoD and achaete-scute have revealed that they heterodimerize with other, ubiquitously expressed bHLH proteins called E12/E47 (Murre et al. 1989b), originally identified as a transcription factor for immunoglobulin genes (Murre et al. 1989a). As E12 appears to be a mammalian homolog of $d a$, the previously observed genetic interac- 
tions between the achaete-scute and da genes (DamblyChaudiere et al. 1988) most likely reflect direct interactions between their protein products.

Recently we isolated cDNAs encoding two mammalian homologs of achaete-scute, called MASHI and MASH2 (Johnson et al. 1990), from MAH cells (Birren and Anderson 1990), a cell line derived from the sympathoadrenal sublineage of the neural crest. The sequences of MASH1 and MASH2 in the bHLH region are more similar to those of achaete-scute than to those of other mammalian bHLH proteins. A similar observation has been made for mammalian and Drosophila MyoD (Michelson et al. 1990). Preliminary studies of MASH1 and MASH2 mRNA expression by Northern blotting in different cell lines and tissues suggested that MASHl, at least, is expressed in the developing nervous system (Johnson et al. 1990). However, these initial experiments did not examine MASHl expression at the cellular level or reveal the precise time, lineage specificity, and spatial pattern of MASH1 expression, nor did they examine the expression of the MASH1 protein.

To address these questions, we have raised specific monoclonal antibodies to MASHl and used them to localize the MASHl protein in developing rat embryos. We find that MASHl expression is specific to the nervous system, but precedes overt neuronal differentiation by 12-24 hr. Moreover, in the brain MASH1 is expressed by subsets of neuroepithelial cells, and in the PNS exclusively by precursors in the sympathoadrenal/enteric sublineage. MASHl expression is transient; the protein disappears concomitantly with the expression of neuronspecific differentiation markers such as neurofilament or SCG10. These features of transient and spatially restricted expression are similar to those exhibited by achaete-scute mRNAs (Cabrera et al. 1987; Romani et al. 1989) and protein (P. Cubas, J.-F. Celis, S. Campuzano, and J. Modolell, in prep.) in Drosophila. This similarity, taken together with the sequence homology between MASHI and achaete-scute, supports the idea that MASHl plays a role in neural determination in vertebrates.

\section{Results}

Isolation and characterization of monoclonal antibodies to MASH1

To obtain specific antibodies to MASH1, we overexpressed the protein in Esherichia coli and immunized mice with gel-purified material (see Materials and methods). From $>800$ hybridomas screened, we obtained $\sim 40$ producing antibodies that reacted specifically with the bacterially expressed protein. Of these, two antibodies, called anti-MASHIA and -MASH1B, reacted with the endogenous MASHl protein in fixed embryo sections (most of the other antibodies failed to do sol. These antibodies also stained the nuclei of PC12 and MAH cells, two cell lines known to express MASH1 mRNA (Johnson et al. 1990), but did not stain RAT1 fibroblasts, which do not express MASH1 mRNA (data not shown).
The data presented here were obtained with antiMASH1A, although anti-MASH1B yielded similar results in selected samples (not shown).

The specificity of the anti-MASHl monoclonal antibodies was characterized in two ways. In the first method, MASH1, MASH2, and a rat E12 protein (S. Birren and D.J. Anderson, unpubl.) were synthesized in a reticulocyte lysate from synthetic mRNA transcribed from their cognate cDNA clones (Fig. 1A, lanes 1-3). Immunoprecipitation with anti-MASH1A revealed reactivity of the antibody toward MASH1 but not toward MASH2 or E12 (Fig. 1A, lanes 4-6). No bands were immunoprecipitated with a control antibody of the same subclass (Fig. 1A, lanes 7-9). Thus, the antibody recognizes MASH1 as distinct from MASH2 or E12. As MASHI and MASH2 are $>90 \%$ identical in their sequence in the bHLH region, this experiment suggests that the epitope detected by anti-MASHlA lies outside this region. This makes it highly unlikely that the antiMASHlA antibody is cross-reactive with other bHLH proteins, which are related primarily in this core region. Similar results were obtained with anti-MASH1B (not shown).

Antibody characterization was also performed by Western blotting. Anti-MASHlA detected a closely spaced $34-\mathrm{kD}$ doublet in MAH cells, the sympathoadrenal progenitor cell line used to isolate the MASHI cDNA [Fig. 1B, lanes 9,10 (arrow)]. This doublet may reflect translational initiation at either of two methionines spaced 7 amino acid residues apart (Johnson et al. 1990) or a post-translational modification. No polypeptides other than MASH1 were detected in MAH cells by the antibody (lane 10; cf. also lanes 4 and 9). No specific band was detected in RAT1 fibroblasts, a control cell line that does not express MASH1 mRNA (Fig. 1B; cf. lanes 8 and 3). The $34-\mathrm{kD}$ doublet was also detected in embryonic day (E) 12.5 and E13.5 brain (Fig. 1B, lanes 6,7), but not liver (cf. lanes 1 and 5), consistent with the specificity of MASH1 mRNA expression in these embryonic tissues (Johnson et al. 1990). Taken together, these data suggest that the anti-MASH1A antibody is highly specific for MASH1 and cross-reacts neither with related bHLH proteins nor with other proteins in cell lines and in embryos.

\section{Expression of MASH1 in the developing CNS}

Rat embryos staged from E7.5 to E13.5 were serially sectioned and stained with monoclonal anti-MASHl. Staining was visualized by using either fluorescently labeled or horseradish peroxidase-conjugated secondary antibody. No specific labeling was detected at any stage prior to E10.5, by which time primary neural induction and neurulation have occurred. MASH1 expression was first detected in the CNS at E10.5, a stage preceding the expression of differentiation markers such as neurofilament (Fig. 2). In the brain, clusters of MASH1-labeled nuclei could be seen in the roof of the presumptive mesencephalon (Fig. 2A, arrow) and the diencephalon (Fig. 
A.

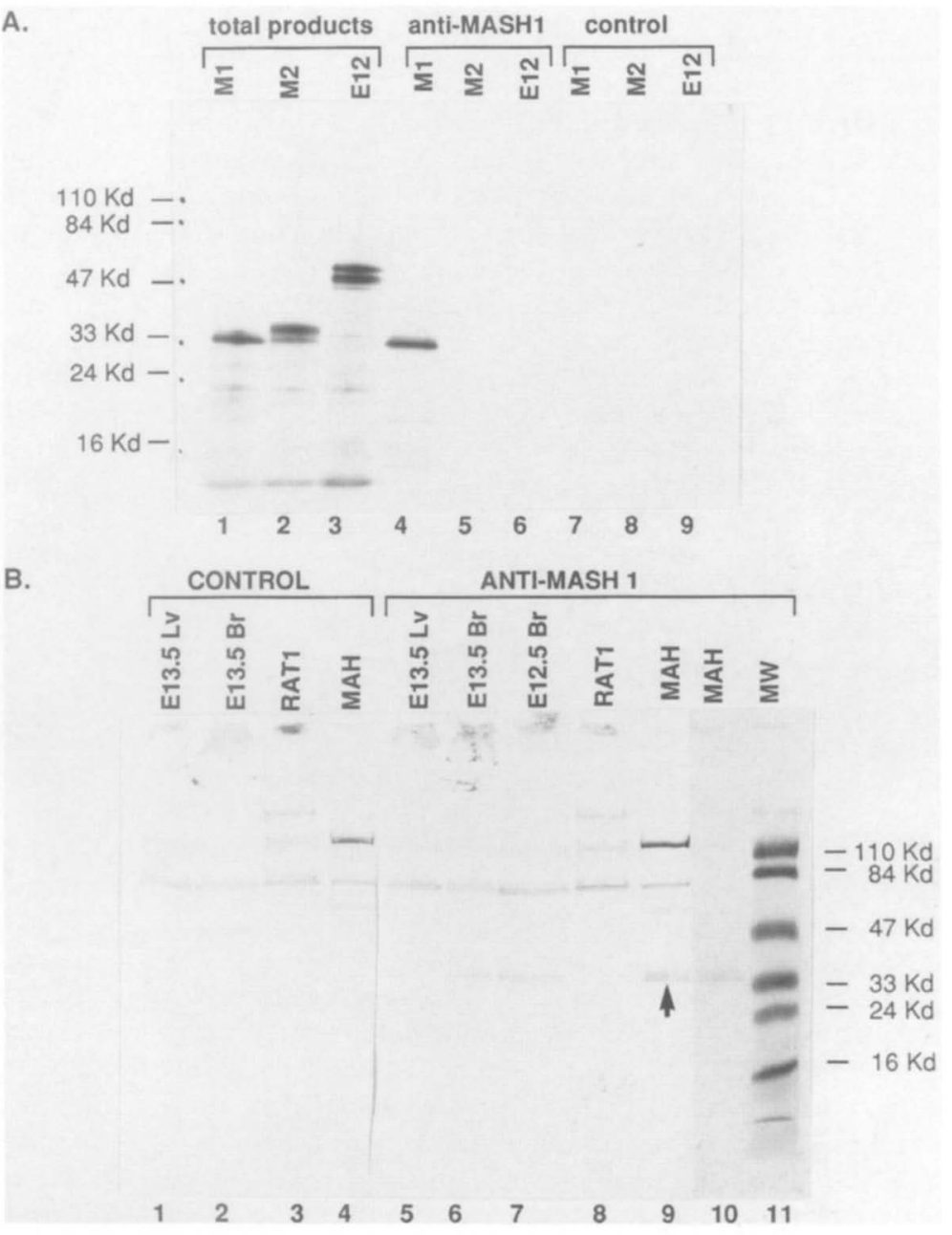

Figure 1. Specificity of anti-MASH1 monoclonal antibodies. (A) Anti-MASHlA does not cross-react with either MASH2 or E12. MASH1 (M1), MASH2 (M2), and $\mathrm{E} 12$ proteins were transcribed and translated in vitro from their respective cDNA clones in the presence of $L-\left[{ }^{35} S\right]$ methionine. Lanes $1-3$ show the total translation products. Aliquots of these reactions were immunoprecipitated with either anti-MASHIA (lanes 4-6) or a control monoclonal IgG (lanes 7-9) and protein G-Sepharose as the immunoadsorbent. The products were analyzed by SDS-PAGE and fluorography. Note that the anti-MASHlA antibody is able to precipitate only the $34-\mathrm{kD}$ MASH1 protein and neither MASH2 nor E12. Molecular masses of standard proteins (Bio-Rad) run in an adjacent lane are indicated at left. $\langle B|$ Western blot analysis of anti-MASHlA specificity. The $34-\mathrm{kD}$ MASH1 doublet is detected in extracts of MAH cells (lane 9, arrow), E12.5 and E13.5 (Br) (lanes 7 and 6, respectively), but not in RAT1 fibroblasts (lane 8) or E13.5 liver (lane 5). This doublet is also seen for in vitro-translated MASHl $(A$, lane 1 ; data not shown.) The higher molecular mass bands on the blot are artifacts of the avidin-biotin method, as shown by control blots lacking primary antibody (lanes 1-4); they are absent if the blot is developed with a less sensitive but more specific HRP-conjugated secondary antibody (lane 10). Although not clearly visible in this reproduction, all bands seen in E13.5 brain except the $34-\mathrm{kD}$ MASH1 doublet (lane 6) were also visible in the control lacking primary antibody (lane 2). Protein (120 $\mu \mathrm{g}$ from each cell line and $300 \mu \mathrm{g}$ from each embryonic tissue) was loaded on the gel. (MW) Molecular mass standards.

2B, arrow). Small clusters of faintly stained nuclei were also observed in the ventral telencephalon (Fig. 2A; data not shown.) In the developing neural tube, a small number of strongly labeled nuclei were visible flanking the floor plate (Fig. 2C,D, arrows.) MASHl expression flanking the floor plate extends rostrally as far as the posterior hindbrain (Fig. 2B, arrowhead) but is not detected in the most caudal regions of the neural tube (Fig. 2A). Occasionally, stained nuclei are observed within the floor plate itself (not shown).

By E11.5, labeled nuclei adjacent to the floor plate have become more numerous (Fig. 3A,C, arrows). At this stage, MASH1 labeling is also detected in the dorsal, but not the intermediate, region of the neural tube (Fig. 3C, arrowheads). When developing motor neurons are visualized by counterstaining sections with antibodies to SCG10, a neuron-specific differentiation marker (Stein et al. 1988), it is apparent that MASHI-positive nuclei occupy a discrete, intermediate region between the floor plate and the SCG10-positive motor neurons (Fig. 3; cf. A with $\mathrm{B}$ and $\mathrm{C}$ with $\mathrm{D}$ ), a region designated as $\mathrm{X}$ by $\mathrm{Ya}$ mada et al. (1991). At this stage of development, SCG10 is not yet detectable in the dorsal neural tube (Fig. 3D), indicating that MASHl expression precedes that of this marker. The segregation of MASH1-positive nuclei to the dorsal and ventral regions of the neural tube suggests that MASHl expression is positionally restricted with respect to the dorsoventral axis of the developing spinal cord. However, the spread of MASH1 expression within the dorsal region varies with anterior-posterior position and with stage of development.

By E13.5, the spinal cord contains a well-defined ventricular zone (Fig. 4B, vz) containing mitotic neuroepithelial precursors. Following their terminal mitosis in the ventricular zone, neuroblasts migrate laterally to the marginal zone (Fig. 4B, mz) where they differentiate. Thus, newly differentiated neurons and their precursors can be visualized simultaneously in spinal cord sections at this stage of development. MASH1-positive nuclei are restricted to the ventricular zone, in the dorsal aspect of the spinal cord (Fig. 4A, arrow). In contrast, cells in the marginal zone expressing terminal differentiation markers such as SCG10 (Fig. 4B) and neurofilament (Fig. 4C) are MASHl negative (Fig. 4A, arrowhead). These observations suggest that MASHl expression not only precedes the expression of terminal differentiation markers 


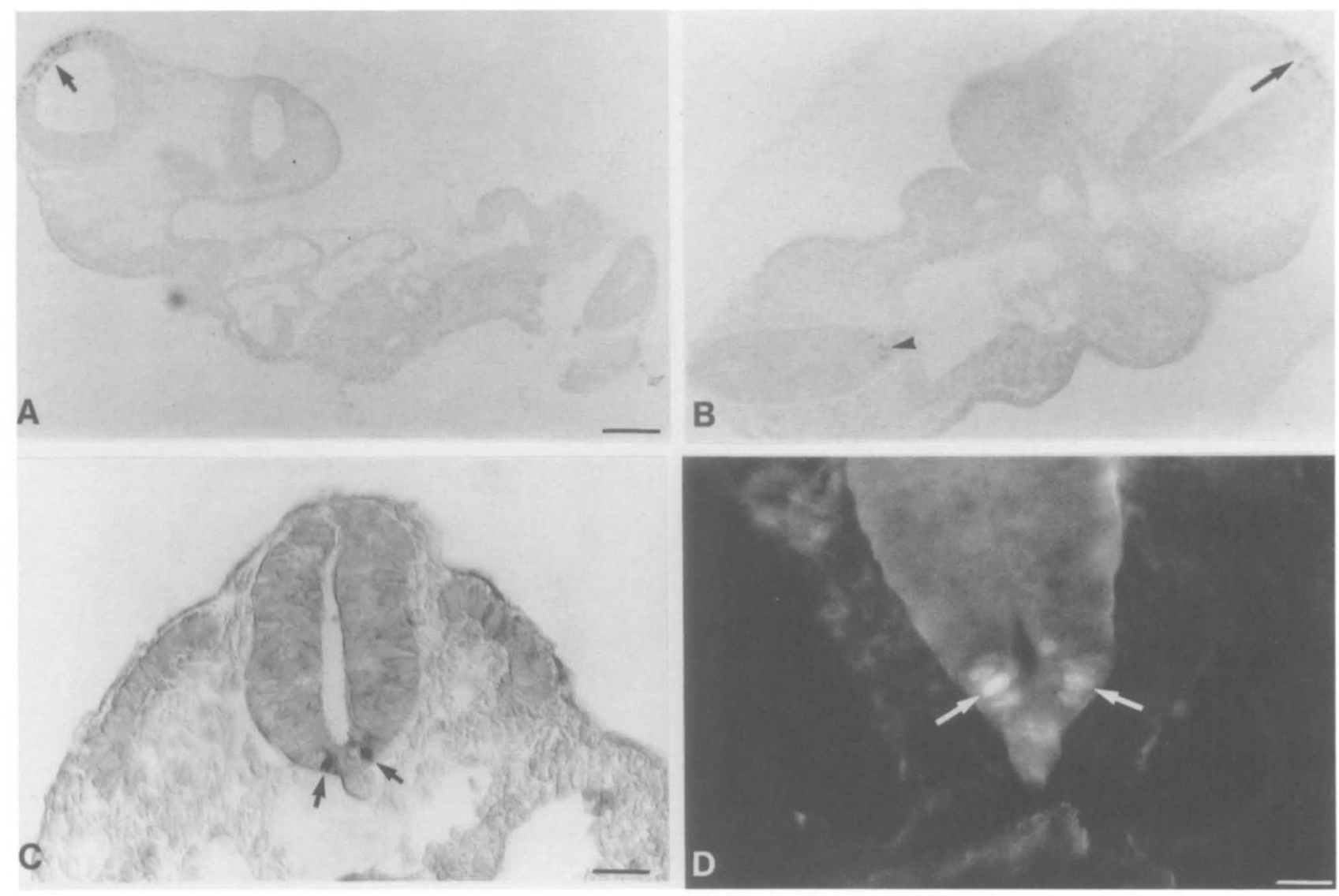

Figure 2. Initial expression of MASH1 is detected in local regions of the E10.5 CNS. $(A, B)$ Frontal sections illustrating MASH1positive nuclei in the roof of the midbrain (arrow, $A$ ) and the roof of the diencephalon (arrow, $B$ ). Immunoperoxidase $(C)$ and immunofluorescence $(D)$ localization of MASH1 immunoreactivity in nuclei (arrows) adjacent to the floor plate in the trunk region of the neural tube. Positive nuclei in the floor plate region are also seen in the hindbrain $(B$, arrowhead). Bars: $(A) 156 \mu \mathrm{m} ;(C) 40 \mu \mathrm{m}$; (D) $32 \mu \mathrm{m}$.

but is also extinguished concomitant with the appearance of such markers.

MASHl expression is also positionally restricted in the developing forebrain. For example, in transverse sections a well-defined, bilaterally symmetric band of labeled nuclei is seen in the E11.5 diencephalon, posterior to the telencephalic boundary [Fig. 5A, di (arrows)]. As in the spinal cord, the MASH1-positive zones in the diencephalon are devoid of neurofilament staining (Fig. 5B). Restricted zones of expression are also visible in the myelencephalon [Fig. 5A, my (arrowheads)]. Some neurofilament staining is visible at this stage in the margins of the myelencephalon (Fig. 5B, arrows), but this staining only partially overlaps the distribution of MASH1-positive nuclei. By E12.5, the band of MASH1 expression in the diencephalon has become more pronounced (Fig. 5C, di). The anterior boundary of this band appears to correlate with the boundary between the diencephalon and telencephalon (located ventral to the section illustrated), but the posterior boundary of the band does not correlate with any structure.

Studies in other systems have suggested that post- transcriptional mechanisms may regulate the expression of some bHLH genes (for review, see Weintraub et al. 1991). We were therefore interested in comparing the pattern of MASH1 mRNA and protein expression. The time of onset of MASH1 protein expression in the brain is similar to that observed for MASH1 mRNA (Johnson et al. 1990). The same appears true of the spatial distribution of MASHl expression. In frontal sections of E13.5 midbrain, the MASHl-positive band in the diencephalon can be seen to extend dorsally to the boundary with the mesencephalon (Fig. 6A, arrowhead). In situ hybridization of similar sections with a MASH1-specific cRNA probe (Fig. 6B) suggests that the distribution of MASH1 mRNA corresponds to that of the MASH1 protein. A similar correspondence between MASHl protein and mRNA expression was also seen in sections of E13.5 spinal cord (data not shown). Thus, the available data fail to suggest evidence of post-transcriptional regulation for MASHl. In this respect the regulation of MASH1 appears similar to that of achaete and scute in the Drosophila wing imaginal disc (P. Cubas et al. 1991).

MASH1-positive nuclei also occupy a spatially re- 

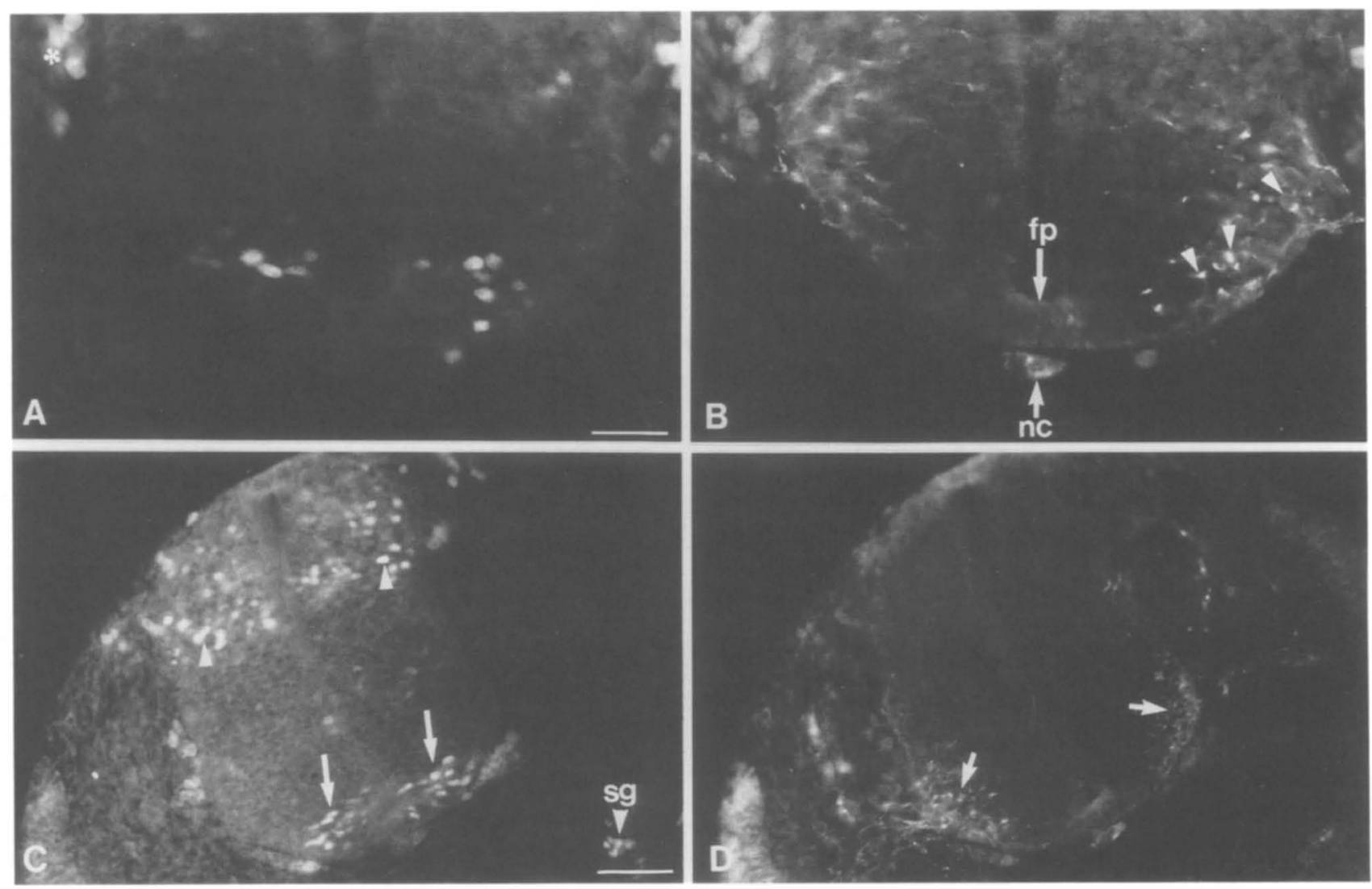

Figure 3. Expression of MASHl in the E11.5 neural tube is distinct from that of a marker of terminal neuronal differentiation. Double-labeling was performed with anti-MASH1 $(A, C)$ and anti-SCG10 $(B, D) \cdot(A, B)$ Ventral region of the neural tube. Note that the MASH1-positive nuclei flank the floor plate $(B, \mathrm{fp})$ and do not overlap the majority of developing motor neurons expressing SCG10 $(B$, arrowheads). (nc), Notochord. (C,D) MASHl is expressed in dorsal ( $C$, arrowheads) as well as ventral (C, arrows) neural tube. Note that SCG10 immunoreactivity has not yet appeared in the dorsal neural tube $(D)$. Asterisk $\left(^{\star}\right)$ in $A$ indicates autofluorescent blood cells; sg in $C$ indicates sympathetic ganglion. Bars: $(A) 43 \mu \mathrm{m}_{;}(C) 85 \mu \mathrm{m}$.

stricted region in the presumptive cortex. In the E12.5 telencephalon, staining is confined to the basal region (Fig. 7D, long arrow.) The posterior boundary of MASH1 expression in the basal telencephalon respects the boundary with the diencephalon (Fig. 7D, arrowhead); however, the anterior boundary of staining is less sharply defined and has no morphologic correlate. The spatial restriction of MASHl expression in the telencephalon is seen more dramatically in serial reconstruction of parasaggital sections [Fig. 7A (tel); C (arrow)). This reconstruction also revealed widespread but patchy staining in the superior colliculus, metencephalon, and myelencephalon (Fig. 7B, arrows). The restricted expression of MASHl in the forebrain does not result from temporal gradients of development, as expression did not extend into the dorsal region of the telencephalon at later stages. Rather, MASH1 expression in the forebrain becomes even more restricted with subsequent development, becoming localized to the presumptive basal ganglia and optic chiasm at E13.5 (not shown). Staining of selected sections of adult brain and olfactory epithelium with
anti-MASH1A has thus far failed to reveal any detectable immunoreactivity (L. Lo, unpubl.).

\section{Expression of MASH1 in the developing PNS}

In the rat, neural crest migration occurs between E10.5E11.5 in the trunk. MASHl expression was not detectable in migrating neural crest cells lateral to the neural tube (Fig. 2C,D and data not shown.) However, by E1111.5 , a population of MASH1-positive nuclei could be observed adjacent to the dorsal aorta, in the sympathetic ganglion anlage (Fig. 8A, arrowheads). Pronounced clustering of these nuclei could be seen in tangential sections (Fig. 8B, arrows). In frontal (longitudinal) sections, the MASH1-positive cells appeared as a regularly spaced chain of clumps bordering the aorta (Fig. 8C, arrows.) In adjacent serial sections, cells in the same position as the MASH1-positive nuclei expressed low-affinity nerve growth factor receptor (LNGFR) (not shown), a surface marker present on many early rat neural crest cells (D. 


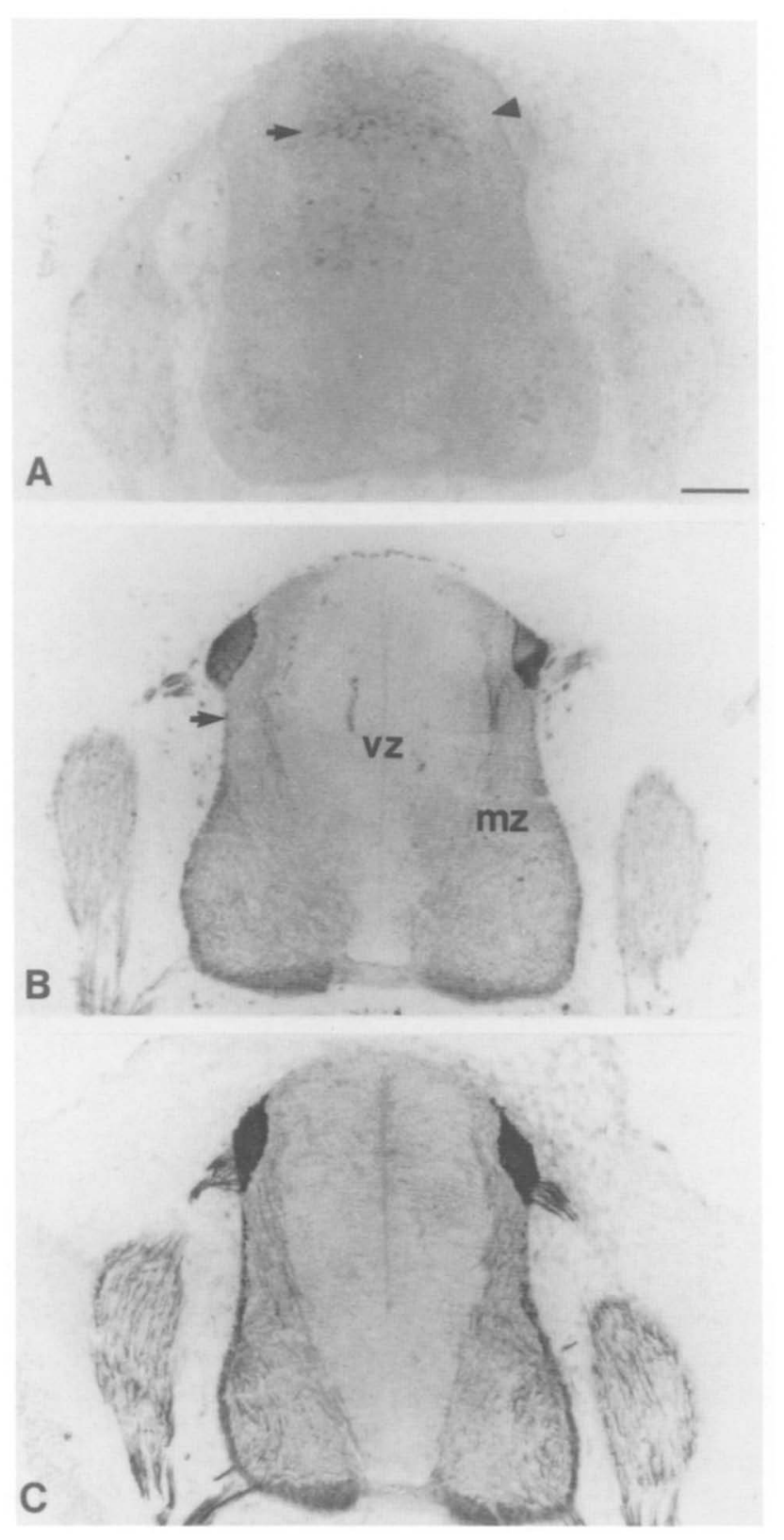

Figure 4. MASH1 expression is restricted to the ventricular zone of the E13.5 neural tube. Consecutive serial sections stained with monoclonal anti-MASHI $(A)$, SCG10 $(B)$ and neurofilament $(C) .(B)\{\mathrm{vz})$ Ventricular zone; $(\mathrm{mz})$ marginal zone. Arrow in $A$ indicates MASH1-positive nuclei in the dorsal ventricular zone; staining is absent from the marginal zone (arrowhead in $A$ ). Conversely, both SCG10 (arrow in $B$ ) and neurofilament $(C)$ are expressed in the marginal zone but not the ventricular zone. Note that by this stage of development, MASH1 staining has disappeared from the floor plate region $|A|$. Bar, 100 $\mu \mathrm{m}$.

Stemple, unpubl.). However, for technical reasons double-labeling with the two antibodies could not be performed. Nevertheless, the position of the MASH1-positive nuclei and their likely coexpression of LNGFR strongly suggest that they are neural crest derived. Scat- tered MASH1-positive cells were also detected ventral to the sympathetic ganglia in the developing gut where enteric neurons are later generated [Fig. 9A /g and small arrows)]. MASH1 staining was not detected at any stage examined in dorsal root ganglia (containing sensory neurons), in the Schwann cells associated with ventral roots, or in the subectodermal region where melanocyte precursors would be found.

The relationship of MASH1 expression to that of other markers expressed by sympathetic neuronal precursors was examined by performing double-labeling experiments. At E11.5, a few weakly SCG10-positive cells could be detected in the area containing MASH1-positive nuclei (Fig. 9C,D, arrows.) It was not possible to determine at this level of resolution whether individual cells coexpressed both markers, although they are clearly present in the same region. A marker specific for sympathetic neurons is tyrosine hydroxylase (TH), the ratelimiting enzyme in catecholamine biosynthesis. Doublelabeling experiments showed no detectable $\mathrm{TH}$ immunoreactivity in the MASH1-positive cell clusters at E1111.5 (not shown.) At E12.5, however, TH was strongly expressed in sympathetic ganglia, in regions overlapping the MASH1-positive nuclei (Fig. 10A,B, short arrows). However, the regions of strongest MASH1 staining appeared to correspond to $\mathrm{TH}$-negative regions /cf. long arrows in Fig. 10A,B). The relative levels of $\mathrm{TH}$ and MASH1 staining in E12.5 sympathetic ganglia differed according to axial position within a given embryo, following the rostrocaudal gradient of neural development: In younger caudal ganglia, loose aggregates of strongly MASH1-positive nuclei could be seen, but few TH-positive cells were visible (Fig. 10C,D, uppermost long arrows); in contrast, in more anterior ganglia, only faint MASHI staining could be seen in the TH-positive ganglia (Fig. 10C,D, lower long arrows). By E13.5, MASH1 staining has essentially disappeared from the ganglia, although occasional positive cells can be seen (data not shown). The reciprocal patterns of MASHl and TH expression in developing sympathetic ganglia strongly suggest that as in the CNS, precursor cells extinguish MASH1 expression as they activate expression of differentiation markers.

\section{Discussion}

The expression pattern of MASH1 is analogous to that of Drosophila achaete-scute

Emerging evidence suggests that bHLH proteins are involved in the process of cell-type determination (Weintraub et al. 1991). In Drosophila, bHLH proteins encoded by the achaete-scute complex are required for the determination of subsets of neurons (for review, see Ghysen and Dambly-Chaudiere 1988). We have used a monoclonal antibody to examine the expression pattern of MASH1, a mammalian protein that shares $88 \%$ amino acid sequence identity with achaete-scute in its bHLH region (Johnson et al. 1990). Our results point to several analogies in the main features of MASHl and achaetescute expression. First, MASH1 is expressed specifically 


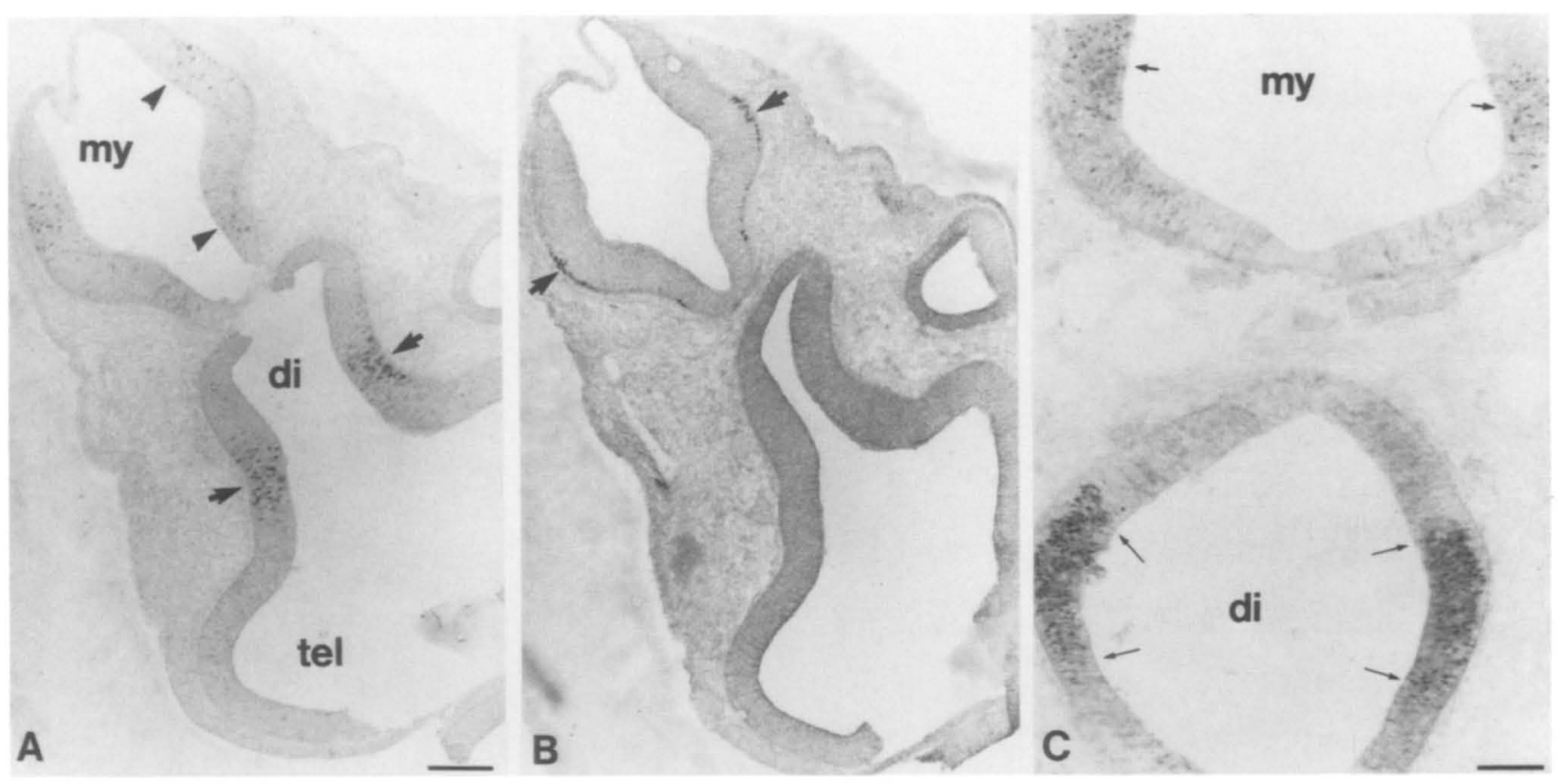

Figure 5. MASHl expression is positionally restricted within the developing forebrain. $(A, B)$ Consecutive transverse sections through E11.5 forebrain stained with anti-MASHI $(A)$ or anti-neurofilament $(B)$. Bands of MASH1-positive nuclei (arrows in $A)$ are visible near the boundary between the diencephalon (di) and telencephalon (tel). No neurofilament staining is apparent in the diencephalon at this stage of development (B). MASHl-positive nuclei (arrowheads in $A$ ) are also apparent in the myelencephalon (my); some neurofilament expression is detectable in the marginal zone (arrows in $B$ ). (C) Transverse section through the myelencephalon (my) and diencephalon (di) of an E12.5 embryo. The plane of section is just dorsal to the outpocketing of the telencephalic vesicles. Note the well-defined boundaries of MASH1 expression in the diencephalon (arrows). Anterior is down; posterior is up. Bars: $(A) 160 \mu \mathrm{m}$; $(C) 125 \mu \mathrm{m}$.

in both the developing CNS and PNS, and the achaetescute genes are required for the development of neurons in both the CNS and PNS. Second, MASHl expression appears to be localized to subsets of neuroepithelial cells. In the Drosophila PNS, the achaete-scute complex is required for the determination of a subset of sensory mother cells that give rise to external sensory (es) organs (Ghysen and O'Kane 1989). Third, expression of MASH1 precedes overt neuronal differentiation, as determined by the expression of neuron-specific markers such as SCG10 and neurofilament. In the Drosophila wing imaginal disc, the achaete protein appears in sensory mother cells two divisions prior to the differentiation of sensory neurons (Romani et al. 1989; P. Cubas et al. 1991). Fourth, MASH1 expression is transient, becoming extinguished at or before overt differentiation. Similarly, in the wing imaginal disc, expression of the achaete protein is extinguished as the sensory mother cells initiate their terminal cell divisions ( P. Cubas et al. 1991). These similarities in MASHl and achaete-scute expression, taken together with their conservation of amino acid sequence, support the notion that MASH1 is a vertebrate neuronal determination gene.

\section{Evolutionary conservation of cell type determination}

The observation that MASHI is expressed specifically in early neuroepithelial precursor cells, like achaete-scute, parallels the observations that the Drosophila and Caenorhabditis elegans homologs of $\mathrm{MyoD}$ are expressed specifically in myogenic precursors, like their vertebrate counterparts (Krause et al. 1990; Michelson et al. 1990). Taken together, these data suggest that there has been a parallel evolutionary conservation of amino acid sequence and cell type specificity for at least some bHLH genes. Such conservation is consistent with the idea (Weintraub et al. 1991) that these genes comprise a family of cell-type determination factors. However, there are differences between the expression patterns of myogenic and neurogenic bHLH genes in their respective lineages. Both MASHl and achaete-scute expression are extinguished at or before overt differentiation. In contrast, the myogenic bHLH genes are expressed not only before but also after the onset of myogenesis (Sassoon et al. 1989). Because myogenic bHLH proteins are able to activate the transcription of muscle-specific structural genes (Lassar et al. 1989), it is thought that they are not only involved in determination but also in differentiation. In contrast, it seems unlikely that MASH1 is directly involved in maintaining the differentiated state. MyoD and MASHl may therefore act in their respective lineages at stages that are overlapping but distinct. Evidence from Drosophila suggests that there are other neural-specific bHLH genes expressed later in development than achaete-scute (Jan and Jan 1990); perhaps the development of neurogenic lineages occurs through a cascade of related genes. 

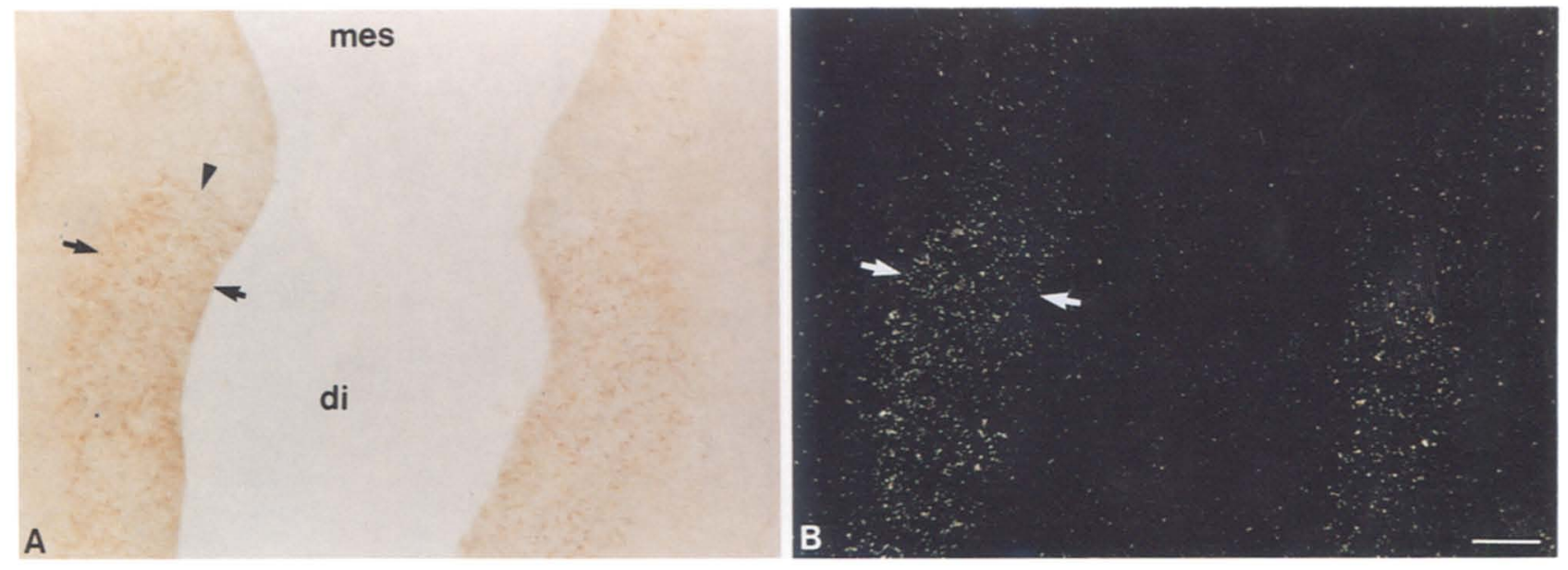

Figure 6. MASH1 mRNA expression corresponds to MASH1 protein expression. (A) Frontal section through E13.5 forebrain just posterior to the telencephalic vesicles, stained with anti-MASHl antibody. The band of labeled nuclei in the ventricular zone of the diencephalon (di) is similar to that seen in Fig. 5C, but the plane of section is perpendicular, revealing the dorsal boundary of staining (arrowhead) near the junction with the mesencephalon (mes). (B) A similar section from a different embryo of the same age was hybridized in situ with a MASH1 antisense cRNA probe (see Materials and methods). A 14-day exposure is shown. Note that the area of high-grain density (arrows) corresponds to that seen with the antibody. Control hybridizations with an antisense SCG10 probe showed grain accumulations over the marginal zone but not in the MASH1-positive ventricular zone (not shown). Bar, $91 \mu \mathrm{m}$.

\section{Control of MASH1 expression}

The pattern of MASH1 expression raises the question of what factor(s) regulate the expression of this presumptive regulatory protein. In the developing spinal cord, MASH1-positive nuclei are found adjacent to the floor plate. A recent series of experiments has revealed that the floor plate possesses an inductive activity that is able to pattern the development of the ventral spinal cord (Yamada et al. 1991), raising the possibility that the floor plate may activate expression of MASHl in adjacent cells. One substance that has been implicated as a possible floor plate-derived inducer is retinoic acid (Wagner et al. 1990). In this respect, it is of interest that MASH1 expression is induced by retinoic acid in P19 cells, an embryonal carcinoma cell line (J.E. Johnson, unpubl.). However, the observation that MASHI is also expressed in the dorsal neural tube implies that the floor plate is not the exclusive inducer of MASHl expression. Rather, MASH1 is likely to be regulated by different factors in different regions of the nervous system.

\section{MASH1 expression as evidence of a prepattern in the developing forebrain}

In the developing CNS, MASH1 appears to be expressed in spatially restricted subsets of neuroepithelial cells. In the forebrain, in particular, restricted zones of MASH1positive nuclei are observed. In some areas, the boundaries of MASHl expression correlate with morphologic boundaries between structures, such as the diencephalon and telencephalon; in other regions, MASHl boundaries exist in a seemingly homogeneous neuroepithelium. The restricted domain of MASH1 expression in the basal tel- encephalon is particularly striking (Fig. 7). Although the telencephalon has not yet been fate-mapped, the region of MASH1 expression may correspond to the presumptive basal ganglia. Spatially restricted domains of transcription factor expression have been shown to precede overt patterning in the hindbrain (Wilkinson et al. 1989) and to correspond to cell lineage compartments (for review, see Lumsden 1990). Recent cell-lineage analyses have supported the existence of compartment-like boundaries to cell mixing along the anteroposterior axis of the forebrain (Austin and Cepko 1990; Crandall and Herrup 1990; Fishell et al. 1990): To our knowledge, the restricted expression of MASH1 represents the first example of spatially restricted transcription factor expression in the embryonic forebrain. It will be necessary to map the fate of the MASH1-expressing cells before the relationship of the expression pattern to cell lineage boundaries or functional subdivisions in the forebrain can be adequately assessed.

\section{MASH1 may be a determination gene for the sympathoadrenal lineage}

The expression of MASH1 in the neural crest-derived sympathoadrenal lineage (Patterson 1990) provides the one system, so far, in which this gene can be linked to the development of a specific neuronal cell type. MASH1-positive nuclei are found in the location where sympathetic neurons will develop, but $24 \mathrm{hr}$ prior to the expression of sympathoadrenal lineage markers. Subsequently, MASH1 expression fades as $\mathrm{TH}$, a marker of sympathoadrenal progenitors (Anderson and Axel 1986), appears. The reciprocal intensities of MASH1 and TH 

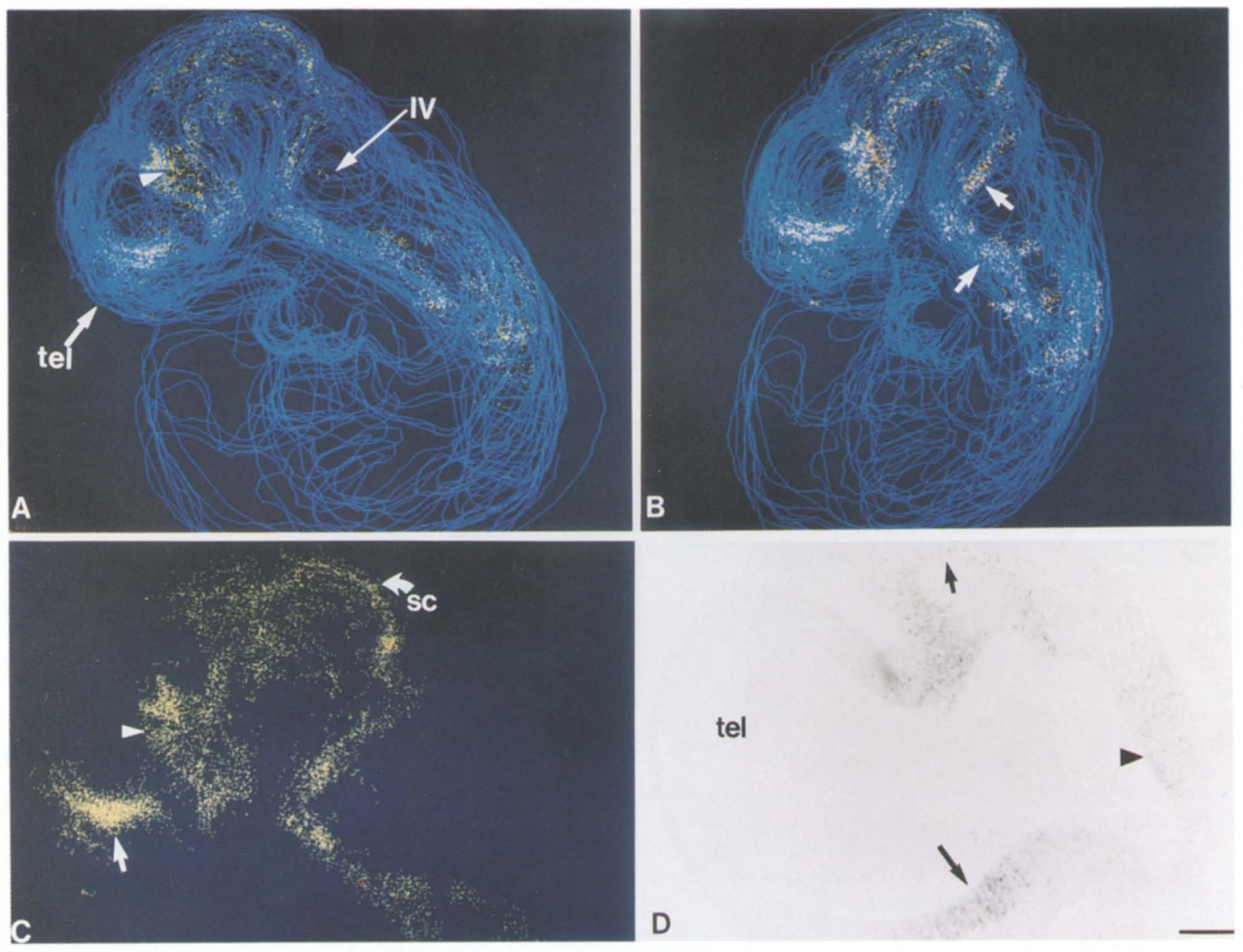

Figure 7. MASH1 expression is positionally restricted in the telencephalon. $(A-C)$ Computer reconstruction of serial parasaggital sections through one-half of an E12.5 embryo stained with anti-MASH1. Blue lines indicate the outlines of individual sections; yellow dots indicate individual nuclei. For simplicity, positive nuclei in the spinal cord have been omitted. The image has been rotated to present two different views in $A$ and $B$. Patches of staining in the hindbrain are more clearly visible in $B$ (arrows). In $C$, the reconstruction is presented without the section outlines; the image has been tilted slightly relative to that in $A$. (tel) Telencephalon; (IV) fourth ventricle; (sc), superior colliculus. Note the domain of positive nuclei in the ventral telencephalon (arrows in $A$ and $C$ ). The arrowhead in $A$ indicates the band of staining in the diencephalon (see also Figs. 5C and 6). (D) Example of one of the parasaggital sections used in the serial reconstruction, indicating restricted domain of MASHl-positive nuclei in the ventral region (long arrow). Anterior is to the left; posterior is to the right. The crescent-shaped band of MASHl expression in the diencephalon is marked by the small arrow. The arrowhead indicates the diencephalon. Bar, $D 160 \mu \mathrm{m}$.

expression within individual ganglia at E12.5 strongly suggest that MASH1-positive cells are developing into TH-positive cells. Expression is not detected in other locations colonized by neural crest cells, with the exception of the gut (see below). The specificity of MASH1 expression in sympathetic ganglia is consistent with the fact that the MASH1 cDNA was initially isolated from MAH cells, an immortalized sympathoadrenal progenitor cell line (Birren and Anderson 1990). In MAH and PC12 cells, however, MASH1 is coexpressed with high levels of TH (Johnson et al. 1990), a cell state not observed in vivo. The immortalized nature of these lines may induce a partial reversion to an earlier stage of development that permits MASH1 expression. Whatever the case, the expression of MASH1 in PC12 and MAH cells clearly does not prevent the expression of later differentiation markers such as TH and SCG10.

In the PNS, MASH1 is also detected in scattered cells within the embryonic gut. One day later in development, cells expressing TH can be observed in the gut, as well (Baetge and Gershon 1989; Baetge et al. 1990). The apparent conversion of MASHl- to TH-expressing cells in sympathetic ganglia suggests a similar lineal relationship for such cells in the gut. It is thought that THexpressing cells in the gut are precursors of enteric neurons (Baetge et al. 1990) and may be similar or identical to sympathoadrenal progenitors (J. Carnahan, D. Anderson, and P. Patterson, in prep.). Taken together, these 

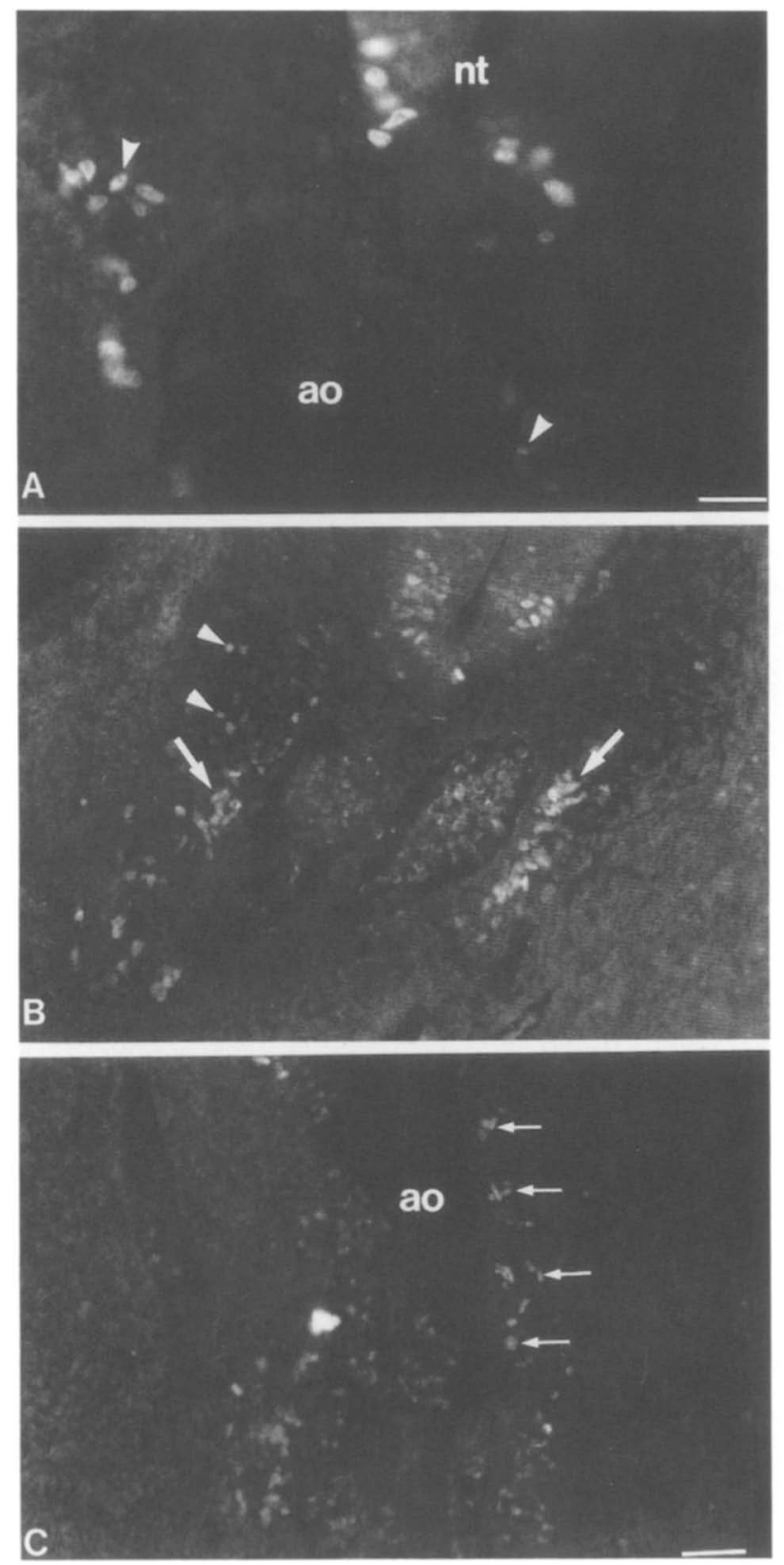

Figure 8. MASHl is expressed in primordial sympathetic ganglia. $(A-C)$ Sections through E11-E11.5 embryos stained for MASHI and visualized by immunofluorescence. (A) Arrowheads indicate positive nuclei aggregating adjacent to dorsal aorta (ao). Note staining in ventral neural tube (nt). (B) Transverse but slightly longitudinal section showing positive nuclei (arrowheads) that appear to be in the process of migrating to the ganglia (arrows.) $(C)$ Longitudinal section showing regularly spaced aggregates of MASHl-postive nuclei (arrows) bordering the dorsal aorta (ao). The bright white patch to the left of the aorta is an artifact. At this stage of development, TH is not yet detectable in the sympathetic ganglia (not shown). Bars: $(A) 32$ $\mu \mathrm{m} ;(C) 64 \mu \mathrm{m}$.

data suggest that MASH1 expression may identify early precursors in the sympathoadrenal/enteric lineage. The facts that MASH1 is expressed one day earlier than terminal differentiation markers and is a transcription factor (J.E. Johnson, S.J. Birren, T. Saito, and D.J. Anderson, unpubl.) raise the possibility that it functions in the determination of this neuronal sublineage. However, the transiently MASH1-positive cells of the sympathetic ganglia could potentially give rise to glia as well as to neurons (as is the case for achaete-scute-expressing precursors in the Drosophila PNS). Because peripheral glia develop in other sites of crest migration where MASH1 is not expressed, the function of MASH1 could, in this case, be to generate both glia and neurons in a particular place (i.e., the sympathetic ganglia) rather than to specify cell type per se. Reverse-genetic experiments in the mouse should provide a means of resolving this question and of determining the extent to which the conservation of sequence and lineage specificity between MASH1 and the achaete-scute genes reflects a true conservation of function.

\section{Materials and methods}

\section{Recombinant pET-MASH1 production}

A MASH1 cDNA was expressed in bacteria under the control of the phage T7 RNA polymerase (Studier et al. 1990). An NcoI site was introduced into the first ATG by site-directed mutagenesis using the Amersham kit, and a restriction fragment extending from this site to a BamHI site $60 \mathrm{bp}$ upstream of the stop codon was cloned into the vector $\mathrm{pET}$. Induction of the recombinant protein was accomplished by the addition of 0.4 mM IPTG. Recombinant MASH1 was the major polypeptide species observed on one-dimensional SDS gels of the inclusion body fraction (not shown). The protein was purified further by preparative electrophoresis and was judged to be essentially free of contaminants upon re-electrophoresis.

\section{Immunization procedures}

Mice were immunized with electroeluted, acetone-precipitated pET-MASHl protein emulsified in complete Freund's adjuvant. A boost without adjuvant was administered after 2 weeks. Each mouse received $75 \mu \mathrm{g}$ of antigen per injection. Three days after the boost, the mouse was sacrificed and its spleen cells fused with HL- 1 myeloma cells. Cells $\left(2 \times 10^{5} /\right.$ well $)$ were plated in 96-well microtiter dishes containing HL-1 serum-free medium with AAT as the selective agent (Kohler and Milstein 1975).

\section{Antibody screening and immunocytochemical studies}

Initial screening of the hybridoma supernatants was carried out by dot blot. One microgram of antigen was spotted on nitrocellulose paper (BA85, $0.45 \mu \mathrm{m}$; Schleicher \& Schuell). The paper was then blocked for $1 \mathrm{hr}$ at room temperature in $3 \%$ gelatin, 10 $\mathrm{mg} / \mathrm{ml}$ of BSA in Tris-buffered saline (TBS), and incubated with hybridoma supernatant overnight at $4^{\circ} \mathrm{C}$, followed by horseradish peroxidase (HRP)-conjugated goat anti-mouse immunoglobulin (Chemicon) at a $1: 200$ dilution. Color development was performed with $0.5 \mathrm{mg} / \mathrm{ml}$ of 4-chloro-1-napthol in $0.01 \%$ hydrogen peroxide for $10 \mathrm{~min}$ at room temperature. Positive mother clones were then rescreened immediately by immunohistochemistry on paraformaldehyde-fixed PC12 and RAT1 fibroblast cells and on frozen sections of E13.5 neural tubes (a stage of development when MASH1 was known to be expressed 

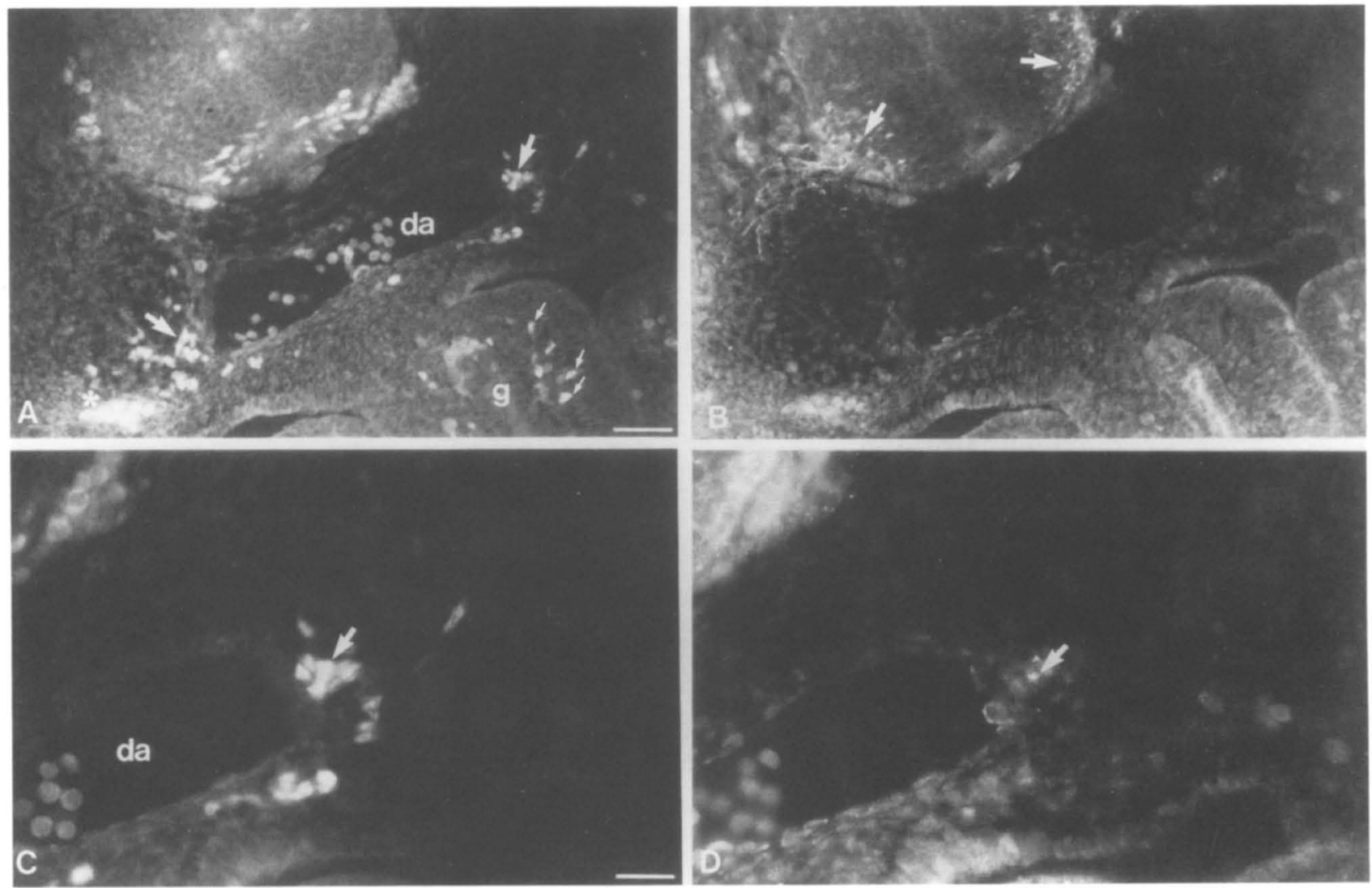

Figure 9. MASH1 is expressed in the developing gut and precedes but overlaps the initial expression of SCG10. E11.5 sections were double-labeled with anti-MASHI $(A, C)$ and anti-SCG10 $(B, D)$. Low $(A, B)$ and high $(C, D)$ magnification views of the same field are shown. In $A$, note the MASHl-positive nuclei (small arrows) migrating into the gut (g). Arrows indicate sympathetic ganglia adjacent to the dorsal aorta (da); the asterisk $\left({ }^{*}\right)$ indicates autofluorescent blood cells. Arrows in $B$ indicate SCG10-positive motor neurons in the neural tube. SCG10 immunoreactivity is detectable $(D$, arrow $)$ in some cells within the same region occupied by MASH1-positive nuclei $(C$, arrow). Sections are from a rostral thoracic region near the bifurcation of the dorsal aorta; in sections from less mature caudal regions, SCG10 immunoreactivity is not yet detectable in MASH1-postive sympathetic ganglia. Bars: $(A) 64 \mu \mathrm{m} ;(C), 32 \mu \mathrm{m}$.

on the basis of earlier Northern blot analysis.) Of 803 wells initially screened, 44 positive mother clones were identified by the dot blot assay. Four of these clones, in turn, exhibited nuclear staining on PC12 but not RATl cells and stained sections of E13.5 embryos; the remainder failed to react with the fixed MASH1 protein in vivo.

For immunocytochemistry, rat embryos aged E7.5-E14.5 (Sprague-Dawley, obtained from Simonsen Breeding Laboratories; age designated as E0.5 the morning following a midnight mating/ were fixed by immersion in freshly prepared $4 \%$ paraformaldehyde in $0.1 \mathrm{M}$ phosphate buffer $(\mathrm{pH} 7.2)$ for at least $\mathrm{l} \mathrm{hr}$ at room temperature, depending on the age of the embryo. Fixation carried out at $4^{\circ} \mathrm{C}$ significantly reduced the sensitivity of staining. Staining intensity was also reduced if embryos were stored in PBS on ice for significant lengths of time during the collection of material, suggesting that the antigen is labile in vivo. Following fixation, embryos were equilibrated in $30 \%$ sucrose in PBS for cryoprotection prior to embedding and cryostat sectioning. Immunoperoxidase staining was performed on frozen sections that were preblocked in $10 \%$ horse serum plus $0.2 \%$ Tween 20 in TBS for $30 \mathrm{~min}$ at room temperature, followed by incubation with hybridoma supernatant diluted $1: 1$ $1: 4$ in TBS with $0.1 \%$ Tween 20 (TTBS) overnight at $4^{\circ} \mathrm{C}$. After being washed twice in TTBS for $15 \mathrm{~min}$ each, sections were developed with an avidin-biotin-HRP system (Vectastain ABC kit, Vector Labs, Burlingame, CA) according to the manufacturer's instructions. Endogenous peroxidase activity was eliminated from the sections by incubating in $0.3 \% \mathrm{H}_{2} \mathrm{O}_{2}$ in methanol for $30 \mathrm{~min}$ at room temperature following binding of the biotinylated secondary antibody. Color development was performed by using diaminobenzidine (DAB). Alternatively, sections were developed for immunofluorescence following primary antibody treatment by incubating with FITC-goat antimouse IgG (TAGO, Inc.) at $1: 200$.

Rabbit antibodies to SCG10 were used at $1: 250$ dilution and visualized by using rhodamine-goat anti-rabbit (TAGO) antibodies at $1: 200$ dilution. Antibody to neurofilament (clone BF10, Boehringer Mannheim Biochemicals) was used at a $1: 40$ dilution and visualized by using biotinylated goat anti-mouse IgG and the Vectastain $A B C$ kit

Data for serial reconstruction of sections were acquired with a motorized microscope stage (Stahl Research) and a digitizer, and stored on an IBM PC-XT. The data were transferred to an Iris 2400 computer (Silicon Graphics, Mountain View, CA), and reconstruction was performed with customized analysis software (J. Knierim and D. Bilitch, unpubl.). 

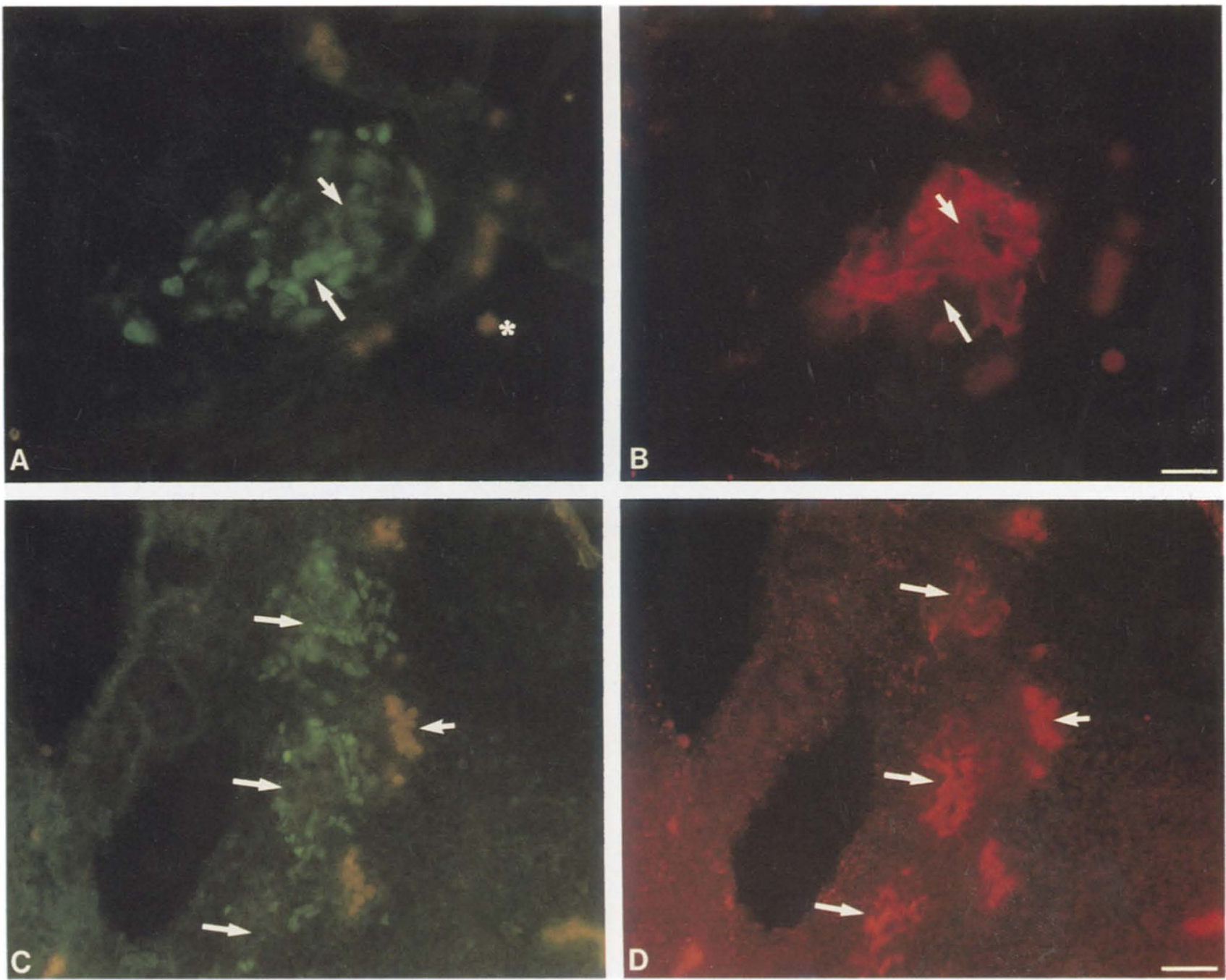

Figure 10. MASH1 expression in sympathetic ganglia overlaps expression of TH. Double-label immunofluorescence of sections through E12.5 sympathetic ganglia stained with anti-MASH $(A, C)$ and anti-TH $(B, D) .(A, B)$ An individual ganglion is shown at high magnification. This ganglion contains a mixture of strongly MASHl-positive ( $A$, long arrow) and weakly positive (A, short arrow) nuclei; these are located in TH-negative $(B$, long arrow $)$ and TH-positive $(B$, short arrow $)$ regions, respectively. The asterisk $\left(^{\star}\right)$ indicates autofluorescent blood cell. $(C, D)$ Semilongitudinal section at lower power, showing three ganglia in a row; caudal is to top; rostral is to the bottom. More caudal ganglia have loosely aggregated, strongly MASH1-positive nuclei (C, top arrow) but are only weakly TH-positive $(D)$; intermediate ganglia have a mixture of MASH1-positive and -negative cells $(C$, middle arrow) and contain TH-positive cells in the central, MASHl-negative region $(D$, middle arrow); more rostral ganglia have few MASHl-positive nuclei $(C)$ and many bright TH-positive cells $(D)$. The short arrows in $C$ and $D$ indicate autofluorescent blood cells. Bars: $(B) 27 \mu \mathrm{m} ;(D) 68 \mu \mathrm{m}$.

\section{In situ hybridization}

In situ hybridization was performed essentially as described previously (Anderson and Axel 1985). The probe used consisted of a 175-bp BamHI fragment containing 60 residues of carboxyterminal-coding sequence and 115 residues of $3^{\prime}$-untranslated sequence. This probe lies $3^{\prime}$ of the bHLH region and does not cross-hybridize with MASH2 or any other related sequences. Antisense riboprobes for in situ hybridization were generated by transcription of BamHI-linearized templates with T7 RNA polymerase.

\section{In vitro transcription and translation}

In vitro transcription and translation of cDNA clones were performed as described (Davis et al. 1990) with a rabbit reticulocyte lysate kit and other reagents from Promega. The MASHl and MASH2 cDNAs containing the complete coding regions were described previously (Johnson et al. 1990). The rat E12 cDNA clone was isolated from a MAH cell cDNA library (S. Birren, unpubl.) and will be described separately (J.E. Johnson, S.J. Birren, T. Saito, and D.J. Anderson, in prep.).

\section{Acknowledgments}

We express our gratitude for the central contribution and expert performance of Susan Ou of the Caltech Monoclonal Antibody Facility, under the direction of Paul Patterson, in producing monoclonal antibodies to MASH1. We thank Karina Cramer for help with the serial reconstruction, the Caltech Graphic Arts 
facility for expert photographic assistance, Helen Walsh for typing, and Barbara Wold, Paul Patterson, John Montgomery, Antonio García-Bellido, and Thomas Jessell for their comments on the manuscript. This work was supported by the Howard Hughes Medical Institute, a Sloan Foundation Faculty Fellowship in Neurosciences (to D.J.A.), a National Science Foundation Presidential Young Investigator Award, and a Searle Scholars Award. J.E.J. is a postdoctoral fellow of the Muscular Dystrophy Association.

The publication costs of this article were defrayed in part by payment of page charges. This article must therefore be hereby marked "advertisement" in accordance with 18 USC section 1734 solely to indicate this fact.

\section{References}

Anderson, D.J. and R. Axel. 1985. Molecular probes for the development and plasticity of neural crest derivatives. Cell 42: 649-662.

. 1986. A bipotential neuroendocrine precursor whose choice of cell fate is determined by NGF and glucocorticoids. Cell 47: 1079-1090.

Austin, C.P. and C.L. Cepko. 1990. Cellular migration patterns in the developing mouse cerebral cortex. Development 110: 713-732.

Baetge, G. and M.D. Gershon. 1989. Transient catecholaminergic (TC) cells in the vagus nerves and bowel of fetal mice: Relationship to the development of enteric neurons. Dev. Biol. 132: 189-211.

Baetge, G., J.E. Pintar, and M.D. Gershon. 1990. Transiently catecholaminergic (TC) cells in the bowel of the fetal rat: Precursors of noncatecholaminergic enteric neurons. Dev. Biol. 141: 353-380.

Birren, S.J. and D.J. Anderson. 1990. A v-myc-immortalized sympathoadrenal progenitor cell line in which neuronal differentiation is initiated by FGF but not NGF. Neuron 4: 189201.

Cabrera, C.V. 1990. Lateral inhibition and cell fate during neurogenesis in Drosophila: The interactions between scute, Notch and Delta. Development 109: 733-742.

Cabrera, C.V., A. Martinez-Arias, and M. Bate. 1987. The expression of three members of the achaete-scute gene complex correlates with neuroblast segregation in Drosophila. Cell 50: $425-433$.

Campuzano, S., L. Carramolino, C.V. Cabrera, M. Ruiz-Gomez, R. Villares, A. Boronat, and J. Modolell. 1985. Molecular genetics of the achaete-scute gene complex of D. melanogaster. Cell 40: 327-338.

Crandall, J.E. and K. Herrup. 1990. Patterns of cell lineage in the cerebral cortex reveal evidence for developmental boundaries. Exp. Neurol. 109: 131-139.

Dambly-Chaudiere., C. and A. Ghysen. 1987. Independent subpatterns of sense organs require independent genes of the achaete-scute complex in Drosophila larvae. Genes \& Dev. 1: 297-306.

Dambly-Chaudiere, C., A. Ghysen, L.Y. Jan, and Y.N. Jan. 1988. The determination of sense organs in Drosophila: Interaction of scute and daughterless. Wilhelm Roux's Arch. Dev. Biol. 197: 419-423.

Davis, R.L., H. Weintraub, and A.B. Lassar. 1987. Expression of a single transfected cDNA converts fibroblasts to myoblasts. Cell 51: 987-1000.

Davis, R.L., P.F. Cheng, A.B. Lassar, and H. Weintraub. 1990. The MyoD DNA binding domain contains a recognition code for muscle-specific gene activation. Cell 60: 773-746.
Fishell, G., J. Rossant, and D. Van der Kooy. 1990. Neuronal lineages in chimeric mouse forebrain are segregated between compartments in the rostrocaudal and radial planes. Dev. Biol. 141: 70-83.

García-Bellido, A. 1979. Genetic analysis of the achaete-scute system of Drosophila melanogaster. Genetics 91: 491-520.

García-Bellido, A. and P. Santamaria. 1978. Developmental analysis of the achaete-scute system of Drosophila melanogaster. Genetics 88: 469-486.

Ghysen, A. and C. Dambly-Chaudiere. 1988. From DNA to form: The achaete-scute complex. Genes \& Dev. 2: 495501.

- 1989. Genesis of the Drosophila peripheral nervous system. Trends Genet. 5: 251-255.

Ghysen, A. and C. O'Kane. 1989. Neural enhancer-like elements as specific cell markers in Drosophila. Development 105: 35-52.

Gonzalez, F., S. Romani, P. Cubas, J. Modolell, and S. Campuzano. 1989. Molecular analysis of the asense gene, a member of the achaete-scute complex of Drosophila melanogaster, and its novel role in optic lobe development. EMBO J. 8: 3553-3562.

Jan, Y.N. and L.Y. Jan. 1990. Genes required for specifying cell fates in Drosophila embryonic sensory nervous system. Trends Neurosci. 13: 493-498.

Johnson, J.E., S.J. Birren, and D.J. Anderson. 1990. Two rat homologues of Drosophila achaete-scute specifically expressed in neuronal precursors. Nature 346: 858-861.

Kohler, G. and C. Milstein. 1975. Continuous cultures of fused cells secreting antibody of predefined specificity. Nature 256: 495-497.

Krause, M., A. Fire, S. Harrison, J. Priess, and H. Weintraub. 1990. CeMyoD accumulation defines the body wall muscle cell fate during C. elegans embryogenesis. Cell 63: 907-919.

Lassar, A.B., J.N. Buskin, D. Lockshon, R.L. Davis, S. Apone, S.D. Hauschka, and H. Weintraub. 1989. MyoD is a sequence-specific DNA binding protein requiring a region of myc homology to bind to the muscle creatine kinase enhancer. Cell 58: 823-831.

Lumsden, A.G.S. 1990. The cellular basis of segmentation in the developing hindbrain. Trends Neurosci. 13: 329-335.

Michelson, A.M., S.M. Abmayr, M. Bate, A.M. Arias, and T. Maniatis. 1990. Expression of a MyoD family member prefigures muscle pattern in Drosophila embryos. Genes \& Dev. 4: 2086-2097.

Moscoso del Prado, J. and A. García-Bellido. 1984. Genetic regulation of the achaete-scute complex of Drosophila melanogaster. Wilhelm Roux's Arch. Dev. Biol. 193: 242-245.

Murre, C., P.S. McCaw, and D. Baltimore. 1989a. A new DNA binding and dimerization motif in immunoglobin enhancer binding, daughterless, $M y o D$ and myc proteins. Cell 56: $777-783$.

Murre, C., P.S. McCaw, H. Vaessin, M. Caudy, L.Y. Jan, Y.N. Jan, C.V. Cabrera, J.N. Buskin, S.D. Hauschka, A.B. Lassar, H. Weintraub, and D. Baltimore. 1989b. Interactions between heterologous helix-loop-helix proteins generate complexes that bind specifically to a common DNA sequence. Cell 58: 537-544.

Patterson, P.H. 1990. Control of cell fate in a vertebrate neurogenic lineage. Cell 62: 1035-1038.

Romani, S., S. Campuzano, E.R. Macagno, and J. Modolell. 1989. Expression of achaete and scute genes in Drosophila imaginal discs and their function in sensory organ development. Genes \& Dev. 3: 997-1007.

Sassoon, D., G. Lyons, W.E. Wright, V. Lin, A.B. Lassar, H. Weintraub, and M. Buckingham. 1989. Expression of two 
myogenic regulatory factors myogenin and MyoD1 during mouse embryogenesis. Nature 341: 303-307.

Stein, R., N. Mori, K. Matthews, L. Lo, and D.J. Anderson. 1988. The NGF-inducible SCG10 mRNA encodes a novel membrane-bound protein present in growth cones and abundant in developing neurons. Neuron 1: 463-476.

Studier, F.W., A.H. Rosenberg, J.J. Dunn, and J.W. Dubendorff. 1990. Use of T7 RNA polymerase to direct expression of cloned genes. Methods Enzymol. 185: 60-89.

Villares, R. and C.V. Cabrera. 1987. The achaete-scute gene complex of D. melanogaster: Conserved domains in a subset of genes required for neurogenesis and their homology to myc. Cell 50: 415-424.

Wagner, M., C. Thaller, T.M. Jessell, and G. Eichele. 1990. Polarizing activity and retinoid synthesis in the floor plate of the neural tube. Nature 345: 819-822.

Weintraub, H., R. Davis, S. Tapscott, M. Thayer, M. Krause, R. Benezra, T.K. Blackwell, D. Turner, R. Rupp, S. Hollenberg, Y. Zhuang, and A. Lassar. 1991. The myoD gene family: Nodal point during specification of the muscle cell lineage. Science 251: 761-766.

Wilkinson, D.G., S. Bhatt, P. Chavrier, R. Bravo, and P. Charnay. 1989. Segment-specific expression of a zinc-finger gene in the developing nervous system of the mouse. Nature 337: 461-464.

Yamada, T., M. Placzek, H. Tanaka, J. Dodd, and T.M. Jessell. 1991. Control of cell pattern in the developing nervous system: Polarizing activity of the floor plate and notochord. Cell 64: 635-647. 


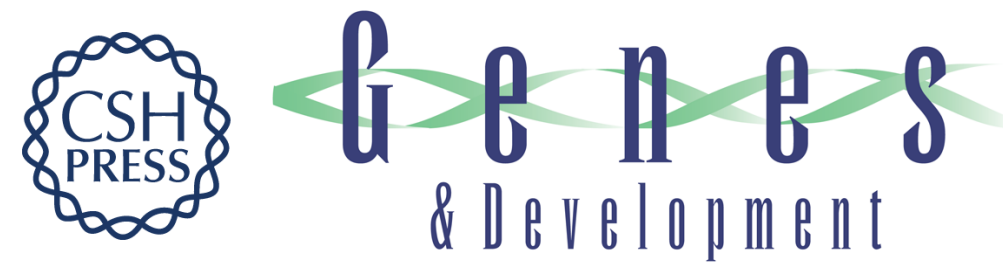

\section{Mammalian achaete-scute homolog 1 is transiently expressed by spatially restricted subsets of early neuroepithelial and neural crest cells.}

L C Lo, J E Johnson, C W Wuenschell, et al.

Genes Dev. 1991, 5:

Access the most recent version at doi:10.1101/gad.5.9.1524

References This article cites 41 articles, 10 of which can be accessed free at: http://genesdev.cshlp.org/content/5/9/1524.full.htmI\#ref-list-1

License

Email Alerting Receive free email alerts when new articles cite this article - sign up in the box at the top Service right corner of the article or click here.

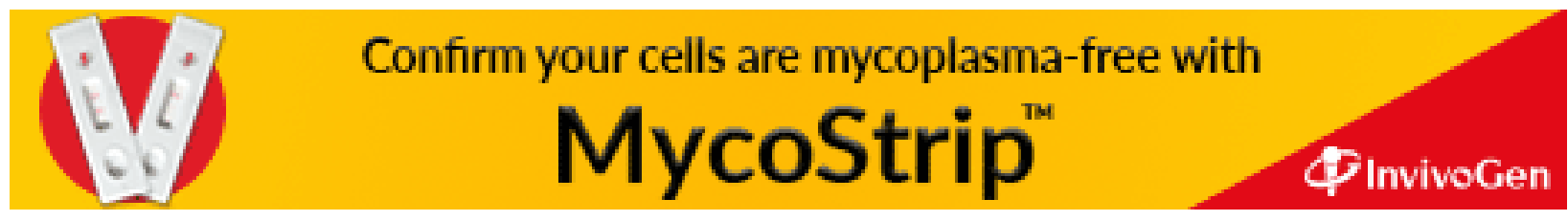

